\title{
A simplified model for the dynamic analysis and power generation of a floating offshore wind turbine
}

\author{
Markus Lerch $^{1, *}$, Mikel De-Prada-Gil ${ }^{1}$, and Climent Molins $^{2}$ \\ ${ }^{1}$ Catalonia Institute for Energy Research, Jardins de les Dones de Negre 1, 2a., 08930 Sant Adrià de \\ Besòs, Barcelona, Spain \\ ${ }^{2}$ Universitat Politècnica de Catalunya, Civil and Environmental Engineering Department, Jordi Girona \\ 1-3, 08034 Barcelona, Spain
}

\begin{abstract}
This paper presents a simplified model for the dynamic analysis of a floating offshore wind turbine (FOWT), which can be suitable for early feasibility and pre-engineering studies, where the complete system has to modeled in order to predict its behavior and to assess the performance. The model solves the equation of motion in time domain and considers Morison equation for computing the hydrodynamic loads. The aerodynamic loads are included by considering the wind thrust at hub height and the loads from the mooring system have been computed as a non-linear model. A methodology is also presented for calculating the structural properties of the system. The model is tested for two load cases and compared to results obtained with the more complex model FAST. The comparison between the response of the models is satisfactory. The simplified model allows to capture the main motions of the FOWT with an acceptable accuracy. A further feature of the model is to calculate the power generation of the floating wind turbine. The results show that the losses in comparison with a bottom-fixed offshore wind turbine are below $1 \%$ or $1.1 \%$ according to the load case, which confirms the good performance of the studied FOWT.
\end{abstract}

\section{Introduction}

Floating substructures for offshore wind turbines are a promising solution that has been under development in recent years. With lower constraints to water depths and soil conditions, floating offshore wind turbines (FOWT) enable to harness the abundant wind resources of deep water areas [1]. As several FOWT concepts have been successfully tested in wave tanks and prototypes have been proven in open seas, floating offshore wind is now reaching a pre-commercial phase where first floating wind turbine arrays are being constructed in European waters [2]. This transition increases the need for comprehensive tools that allow to model the complete system and to predict its behavior as well as to assess the performance. There exist software packages that allow to model wind turbines with a high fidelity and complexity level [3]. However, such programs are either only commercially available or require a comprehensive technical background to be used. The objective of this paper is to present a simpler numerical model that allows capturing the main motions of a FOWT to different met-ocean conditions. In addition, the power generation is obtained considering the specific behavior of the FOWT and compared to a bottom-fixed offshore wind turbine (BOWT). The FOWT studied is the OC3 (Offshore Code Comparison Collaboration) Hywind Spar buoy concept as defined in detail in Ref. [4]. This paper is organized as follows. Section 2 , presents the methodologies used in the numerical model. In Section 3, the developed model is validated against the software FAST by performing a dynamic analysis of the FOWT and comparing the results to ones obtained in the research project OC3 [5]. In Section 4, the main conclusions of this paper are summarized.

\footnotetext{
*Corresponding author: mlerch@irec.cat
} 


\section{Methodology}

\subsection{Model description}

The developed model considers the FOWT as a single rigid body subject to environmental loads and neglects structural deflections by assuming infinite stiffness. This allows for a significant simplification of the model [6]. The dynamic analysis of the FOWT is performed by solving the equation of motion in time domain as follows:

$$
(M+A) \ddot{x}(t)+B \dot{x}(t)+(C) x(t)=F_{\text {ext }}(t)
$$

where the motion vector $x(t)$ represents the displacements in each degree of freedom (DOF). For a FOWT there are typically six rigid-body DOF. Due to the symmetry of the Spar buoy concept and in order to simplify the model only the surge, heave and pitch motions are considered. $B$ is the damping and $C$ the hydrostatic stiffness. All those before mentioned are $3 \times 3$ matrices according to the selected DOF. $F_{\text {ext }}$ represents the vector of all external forces and moments acting on the FOWT [3]. In order to solve Eq. 1 all the loads and forces have to be identified. The modeling of the external forces is presented in Section 2.2. The methodology for computing the structural properties of the left side of the equation is presented in Section 2.3. Once the equation of motion is completely defined, it is written in the state-space form in order to eliminate the second order differential equations. Afterwards, ode45 function from MATLAB can be used to solve it.

\subsection{Load description}

The forces that act on the FOWT consist of aerodynamic, hydrostatic and hydrodynamic loads as well as the mooring system [3]. Wind and waves are considered as main environmental loads in this study.

\subsubsection{Aerodynamics}

The aerodynamic loading on a wind turbine depends mainly on the wind velocity and the rotor characteristics. The wind thrust force acting on the FOWT is given as:

$$
F_{\text {wind }}=\frac{1}{2} \rho_{\mathrm{a}} \pi \frac{A_{\text {rotor }}^{2}}{4} C_{\mathrm{T}} v_{\text {rel }}^{2} \text { with } v_{\text {rel }}=v_{\text {wind }}-v_{\text {hub }}
$$

where $\rho_{a}$ represents the air density, $D_{\text {rotor }}$ is the diameter of the rotor, $C_{T}$ the thrust coefficient and $v_{r e l}$ the relative wind velocity at hub height. The relative wind velocity is the wind velocity reduced by the hub velocity $v_{h u b}$ due to the motions of the substructure. The thrust coefficient is in general a function of the blade tip-speed ratio and the blade pitch angle [7]. This approach has been used in Section 2.4 to calculate the power generation. In regard to the modeling of the structural behavior, a simplified approach was used by considering the dependence of the thrust coefficient only on the wind speed as follows:

$$
C_{\mathrm{T}}=\left[\begin{array}{cc}
C_{\mathrm{T} 0} & \text { if } v_{\text {rel }} \leq v_{\text {rated }} \\
C_{\mathrm{T} 0} e^{\left(-\mathrm{a}\left(\mathrm{v}_{\mathrm{rel}}-\mathrm{v}_{\mathrm{rated}}\right)^{\mathrm{b}}\right)} & \text { if } v_{\text {rel }}>v_{\text {rated }}
\end{array}\right]
$$

where $C_{T 0}$, a and b are constants. The applied approach allows to maximize the thrust force up to rated wind speed $v_{\text {rated }}$ by keeping $C_{T}$ constant. After rated wind speed, the thrust coefficient is exponentially reduced. 


\subsubsection{Hydrostatics}

The hydrostatic loads on the platform refer to the effect of having a submerged body in water. It can be divided into an undisturbed buoyancy force and a restoring term due to the platform movements. The restoring term is the hydrostatic stiffness $\mathrm{C}$ of Eq. 1 and its computation is defined in Section 2.3. The buoyancy force is a vertical force directed upwards and according to Archimedes' principle possesses a value equal to the volume of fluid displaced by the body [8] and can be obtained as:

$$
F_{\text {buoy }}=\rho_{\mathrm{w}} g V
$$

$$
F_{\mathrm{G}}=-m_{\mathrm{t}} g
$$

where $\rho_{w}$ represents the water density, $g$ the gravitational acceleration and $\mathrm{V}$ the displaced submerged volume of the Spar. The force that balances the buoyancy is the weight and is obtained by considering the total mass $m_{t}$ of the FOWT [4].

\subsubsection{Hydrodynamics}

Morison equation has been applied to calculate the hydrodynamic loads acting on the FOWT. It is one of the widely used methods for slender structures like the Spar and aims to address viscous effects as well as inertial loads by an empirically derived formula [9]. Eq. 6 presents the Morison equation in conjunction with strip theory by dividing the structure in discrete elements of $d z$. The total force is obtained by integrating $d F$ over the length of the Spar [8].

$$
d F_{\mathrm{h}}=\frac{1}{2} \rho_{\mathrm{w}} C_{\mathrm{d}} D d z\left|v_{\mathrm{r}}\right| v_{\mathrm{r}}+C_{\mathrm{a}} \rho_{\mathrm{w}} A(z) d z a_{\mathrm{r}}+A(z) d z \rho_{\mathrm{w}} a_{\mathrm{W}}
$$

The hydrodynamic added mass and viscous-drag coefficients are represented by $C_{d}$ and $C_{a}$, respectively. The term $D d z$ is the frontal area of the strip and $A d z$ is the displaced volume of fluid for the corresponding strip. $v_{r}$ is the relative velocity between the water particle velocity $v_{W}$ and the velocity of the body $v_{B}$ [8]. The equation does not account for the hydrodynamic heave force experienced by the FOWT. The heave force can be approximated by the change of the hydrostatic pressure caused by the variation of wave elevation $\eta$ at the water-plane area $A_{w p}$ as follows [4]:

$$
F_{\mathrm{p}}=\rho_{\mathrm{w}} g \eta A_{\mathrm{wp}}
$$

\subsubsection{Mooring system}

The mooring loads are modeled by using the quasi-static analysis approach, which considers the offset of the floating structure caused by wave-induced motions and the computation of the non-linear catenary stiffness [10]. The mooring line is taken as a continuous cable with homogeneous properties. However, forces arising from inertia, viscous drag, internal damping, bending and torsion are neglected [11]. The quasi-static model is applied, because it provides a reasonable approximation of the mooring load and a simple calculation methodology compared with a fully dynamic model. As the structure is being displaced, the fairlead position moves at a height $h$ and length 1 and provokes a resulting horizontal and vertical force at the fairlead from the mooring load. Eq. 8 and 9 are used to obtain the fairlead forces for a fully suspended mooring line [12].

$$
\begin{gathered}
l=\frac{X}{w}\left(\ln \left(\frac{Z}{X}+\sqrt{1+\left(\frac{Z}{X}\right)^{2}}\right)-\ln \left(\frac{Z-w L}{X}+\sqrt{1+\left(\frac{Z-w L}{X}\right)^{2}}\right)\right)+\frac{X L}{E A} \\
h=\frac{X}{w}\left(\sqrt{1+\left(\frac{Z}{X}\right)^{2}}-\sqrt{1+\left(\frac{Z-w L}{X}\right)^{2}}\right)+\frac{1}{E A}\left(Z L-\frac{w L^{2}}{2}\right)
\end{gathered}
$$


$X$ represents the horizontal and $Z$ the vertical component of the fairlead force. The unstretched line length is given as $L$ and $w$ represents the weight per unit length of the mooring line in the water. $E A$ is the cross-section axial stiffness. The system of nonlinear equations is solved for a range of possible displacements of the fairlead and by using the solver fsolve from MATLAB. When the vertical force $Z$ is less than the total weight of the cable, then a portion of the mooring line will rest on the seabed and the equations have to be slightly modified as defined in Ref. [12]. The total mooring load on the structure is obtained by considering the fairlead forces of all three mooring lines.

\subsection{Structural properties}

The mass and added mass matrix is obtained as follows [9]:

$$
M=\left[\begin{array}{ccc}
m_{\mathrm{t}} & 0 & m_{\mathrm{t}} z_{\mathrm{CoM}} \\
0 & m_{\mathrm{t}} & -m_{\mathrm{t}} x_{\mathrm{CoM}} \\
0 & -m_{\mathrm{t}} x_{\mathrm{CoM}} & I_{\mathrm{yy}}
\end{array}\right] \quad A=\left[\begin{array}{ccc}
\int_{z_{\mathrm{bot}}}^{0} \rho_{\mathrm{w}} C_{\mathrm{a}} A(z) d z & 0 & \int_{z_{\mathrm{bot}}}^{0} \rho_{\mathrm{w}} C_{\mathrm{a}} A(z) z d z \\
0 & \frac{2}{3} \rho_{\mathrm{w}} \pi R^{3} & 0 \\
\int_{z_{\mathrm{bot}}}^{0} \rho_{\mathrm{w}} C_{\mathrm{a}} A(z) z d z & 0 & \int_{z_{\mathrm{bot}}}^{0} \rho_{\mathrm{w}} C_{\mathrm{a}} A(z) z^{2} d z
\end{array}\right]
$$

where $m_{t}$ is the total mass of the FOWT, $x_{C o M}$ the center of mass and $I_{y y}$ represents the pitch inertia. The added mass is additional mass that the structure appears to have when it is accelerated relative to the surrounding water. Strip theory is used to calculate the added mass for each DOF using constant added mass coefficients of two dimensional sections and integrating over the length [13]. $C_{a}$ represents the added mass coefficient and $A(z)$ the crosssectional area of the Spar structure. Ref. [4] recommends to add linear damping to capture correctly the response of the OC3-Hywind concept to hydrodynamic loads. The damping for surge and heave are $1.0 \mathrm{e}^{5} \mathrm{~N} \mathrm{~s} / \mathrm{m}$ and $1.3 \mathrm{e}^{5} \mathrm{~N} \mathrm{~s} / \mathrm{m}$, respectively. The hydrostatic stiffness represents the restoring term as effect of the substructure movements in the water in heave and pitch direction and is computed as follows, where $\mathrm{z}_{\mathrm{CoB}}$ is the center of buoyancy [14].

$$
C=\left[\begin{array}{cccc}
0 & 0 & 0 & \\
0 & \rho_{\mathrm{w}} g A_{\mathrm{wp}} & 0 & \\
0 & 0 & & \rho_{\mathrm{w}} g I_{\mathrm{wp}}+\rho_{\mathrm{w}} g V z_{\mathrm{CoB}}-m_{\mathrm{t}} g z_{\mathrm{CoM}}
\end{array}\right]
$$

\subsection{Power generation}

The power generated by the FOWT can be calculated by Eq. 12 taking into account the rotor swept area $A_{\text {rotor }}$, the power coefficient $C_{p}$ and the wind speed $v_{\text {wind }}$ at hub height. The power coefficient depends on the blade tip-speed ratio $\lambda$ and the blade pitch angle $\beta$ [7].

$$
P_{\mathrm{FOWT}}=\frac{1}{2} \rho_{\mathrm{a}} A_{\text {rotor }} C_{\mathrm{p}}(\lambda, \beta)\left(v_{\text {wind }} \cos (\theta)\right)^{3}
$$

For the case of a FOWT two considerations have been included. The first is that the motions of the FOWT provoke an additional mean platform tilt angle. This causes the rotor to be slightly titled against the inflow wind velocity. This effect is taken into account in the power calculation by reducing the wind velocity by the pitch angle $\theta$ of the structure [3]. The second consideration is that the model takes into account the relative wind velocity in the pitch computation of the FOWT as outlined in Section 2.2.1.

\section{Model validation}

\subsection{Static sizing}

In this section, the obtained static properties of the FOWT are presented and compared with the ones computed by FAST in the OC3 project [15]. 


$$
\left[\begin{array}{lll}
8.07 e^{6} \mathrm{~kg} & 0 & -6.29 e^{8} \mathrm{~kg} \mathrm{~m} \\
0 & 8.07 e^{6} \mathrm{~kg} & 1.12 e^{5} \mathrm{~kg} \mathrm{~m}^{2} \\
-6.29 e^{8} \mathrm{~kg} \mathrm{~m} & 1.12 e^{5} \mathrm{~kg} \mathrm{~m} & 6.80 e^{10} \mathrm{~kg} \mathrm{~m}^{2}
\end{array}\right]\left[\begin{array}{lll}
8.07 e^{6} \mathrm{~kg} & 0 & -6.29 e^{8} \mathrm{~kg} \mathrm{~m} \\
0 & 8.07 e^{6} \mathrm{~kg} & 1.12 e^{5} \mathrm{~kg} \mathrm{~m}^{8} \\
-6.29 e^{8} \mathrm{~kg} \mathrm{~m} & 1.12 e^{5} \mathrm{~kg} \mathrm{~m} & 6.80 e^{10} \mathrm{~kg} \mathrm{~m}^{2}
\end{array}\right]
$$

Mass computed by FOWAT

Mass computed by FAST

The mass matrix calculated by the developed model agrees well with the one obtained by FAST $[4,16]$. The obtained added mass matrix is presented next and compared to the results from FAST for zero frequency [4].

$$
\left[\begin{array}{lll}
7.98 e^{6} \mathrm{~kg} & 0 & -4.94 e^{8} \mathrm{~kg} \mathrm{~m} \\
0 & 2.23 e^{4} \mathrm{~kg} & 0 \\
-4.94 e^{8} \mathrm{~kg} \mathrm{~m} & 0 & 3.97 e^{10} \mathrm{~kg} \mathrm{~m}^{2}
\end{array}\right]\left[\begin{array}{lll}
\approx 8.00 e^{6} \mathrm{~kg} & 0 & \approx-4.90 e^{8} \mathrm{~kg} \mathrm{~m} \\
0 & \approx 2.00 e^{4} \mathrm{~kg} & 0 \\
\approx-4.90 e^{8} \mathrm{~kg} \mathrm{~m} & 0 & \approx 3.90 e^{10} \mathrm{~kg} \mathrm{~m}^{2}
\end{array}\right]
$$

Added mass computed by FOWAT

Added mass by FAST approximated

The mooring stiffness matrix obtained by FOWAT is shown next. The accuracy of the developed model is quite high for the mooring stiffness calculation in comparison to FAST.

$$
\left[\begin{array}{lll}
4.12 e^{4} \mathrm{~N} / \mathrm{m} & 0 & -2.82 e^{6} \mathrm{~N} / \mathrm{rad} \\
0 & 1.19 e^{4} \mathrm{~N} / \mathrm{m} & 0 \\
-2.82 e^{6} \mathrm{~N} / \mathrm{m} & 0 & 3.11 e^{8} \mathrm{~N} \mathrm{~m} / \mathrm{rad}
\end{array}\right]\left[\begin{array}{lll}
4.12 e^{4} \mathrm{~N} / \mathrm{m} & 0 & -2.82 e^{6} \mathrm{~N} / \mathrm{rad} \\
0 & 1.19 e^{4} \mathrm{~N} / \mathrm{m} & 0 \\
-2.82 e^{6} \mathrm{~N} / \mathrm{m} & 0 & 3.11 e^{8} \mathrm{~N} \mathrm{~m} / \mathrm{rad}
\end{array}\right]
$$

Mooring stiffness computed by FOWAT

Mooring stiffness computed FAST

The obtained hydrostatic matrix is shown next. The hydrostatic stiffness in pitch considers only the effect of the hydrostatic pressure as defined in the OC3 report Ref. [4]. The results of both models are in good agreement.

$$
\left[\begin{array}{lll}
0 & 0 & 0 \\
0 & 3.34 e^{5} \mathrm{~N} / \mathrm{m} & 0 \\
0 & 0 & -5.01 e^{9} \mathrm{Nm} / \mathrm{rad}
\end{array}\right] \quad\left[\begin{array}{lll}
0 & 0 & 0 \\
0 & 3.33 e^{5} \mathrm{~N} / \mathrm{m} & 0 \\
0 & 0 & -4.99 e^{9} \mathrm{~N} \mathrm{~m} / \mathrm{rad}
\end{array}\right]
$$

Hydrostatic stiffness computed by FOWAT Hydrostatic stiffness computed by FAST

Based on the previously presented static matrices, the natural frequencies and periods of the FOWT are computed and presented in Table 1.

Table 1: Natural frequencies and periods

\begin{tabular}{lllllll}
\hline & $\begin{array}{l}\text { Surge } \\
\text { Frequency }\end{array}$ & $\begin{array}{l}\text { Heave } \\
\text { Frequency }\end{array}$ & $\begin{array}{l}\text { Pitch } \\
\text { Frequency }\end{array}$ & $\begin{array}{l}\text { Surge } \\
\text { Period }\end{array}$ & $\begin{array}{l}\text { Heave } \\
\text { Period }\end{array}$ & $\begin{array}{l}\text { Pitch } \\
\text { Period }\end{array}$ \\
\hline FOWAT & $0.008 \mathrm{~Hz}$ & $0.033 \mathrm{~Hz}$ & $0.033 \mathrm{~Hz}$ & $124.003 \mathrm{~s}$ & $30.002 \mathrm{~s}$ & $30.776 \mathrm{~s}$ \\
FAST & $0.008 \mathrm{~Hz}$ & $0.032 \mathrm{~Hz}$ & $0.034 \mathrm{~Hz}$ & $125.000 \mathrm{~s}$ & $31.250 \mathrm{~s}$ & $29.412 \mathrm{~s}$ \\
\hline
\end{tabular}

The surge frequency obtained from the FOWAT model matches the value calculated in the OC3 report in Ref. [5]. The frequency in heave is slightly higher than the reference one and the pitch is slightly lower. However, the differences are smaller than $3 \%$ and the accuracy of the developed model is seen to be sufficient for the purpose of this study.

\subsection{Dynamic analysis}

In this section, the dynamic response of the FOWT to two load cases (LC) is computed. The LC are based on the OC3 Phase IV study (Ref. [15]) where different modeling codes have been compared.

\subsubsection{Load case 1}

The first LC is used to analyze the behavior of the FOWT based on the excitation by a steady wind force of $8 \mathrm{~m} / \mathrm{s}$ and regular airy waves of $6 \mathrm{~m}$ height and $10 \mathrm{~s}$ period. The time response for the non-transient part is shown in Fig. 1. 

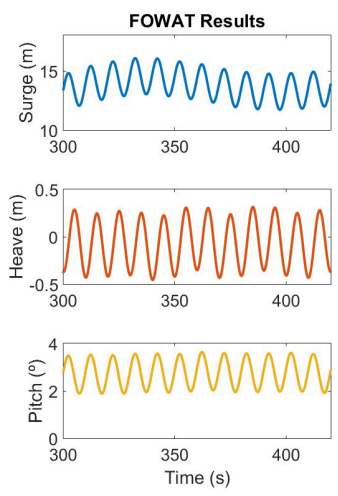

Fig. 1. Non-transient response
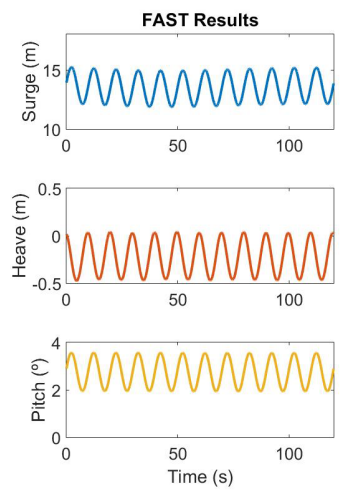

\begin{tabular}{lcc} 
& FOWAT & FAST \\
\hline Surge & $13.68 \mathrm{~m}$ & $13.54 \mathrm{~m}$ \\
Heave & $-0.07 \mathrm{~m}$ & $-0.22 \mathrm{~m}$ \\
Pitch & $2.74^{\circ}$ & $2.75^{\circ}$ \\
\hline
\end{tabular}

Table 2: Mean displacements

It can be observed that the system oscillates around the equilibrium position and with the wave frequency in all degrees of freedom. The oscillation with the natural frequencies is also visible. Besides that, it can be seen that the wind force generates an offset in both the surge and pitch DOF, which causes the equilibrium point to be different than zero for these two. The average values for the non-transient part obtained with the developed model and FAST are presented in Table 2. The values are close to the ones obtained with FAST, which allows to conclude that the aerodynamic effect is correctly captured by the model.

\subsubsection{Load case 2}

LC 2 is used to study the effect of irregular waves and turbulent wind based. JONSWAP spectrum is used to create the irregular wave profile with a significant wave height of $6 \mathrm{~m}$ and a peak-spectral wave period of 10s. The turbulent wind, based on the Kaimal spectrum, has a mean wind speed equal to the rated speed of $11.4 \mathrm{~m} / \mathrm{s}$ and a turbulence intensity of 0.14 . Since the irregular wave profile is a superposition of waves with different frequencies, the response of the FOWT is shown as statistical parameters in Table 3.

Table 3: Response comparison between FOWAT and FAST

\begin{tabular}{llccccc}
\hline & & Wind & Wave & Surge & Heave & Pitch \\
\hline Minimum & FOWAT & $6.28 \mathrm{~m} / \mathrm{s}$ & $-4.54 \mathrm{~m}$ & $14.67 \mathrm{~m}$ & $-0.83 \mathrm{~m}$ & $0.18^{\circ}$ \\
& FAST & $6.60 \mathrm{~m} / \mathrm{s}$ & $-5.84 \mathrm{~m}$ & $11.38 \mathrm{~m}$ & $-1.07 \mathrm{~m}$ & $1.33^{\circ}$ \\
Mean & FOWAT & $11.11 \mathrm{~m} / \mathrm{s}$ & $0.01 \mathrm{~m}$ & $23.79 \mathrm{~m}$ & $-0.21 \mathrm{~m}$ & $4.74^{\circ}$ \\
& FAST & $11.43 \mathrm{~m} / \mathrm{s}$ & $0.01 \mathrm{~m}$ & $21.19 \mathrm{~m}$ & $-0.47 \mathrm{~m}$ & $4.25^{\circ}$ \\
Maximum & FOWAT & $16.16 \mathrm{~m} / \mathrm{s}$ & $4.73 \mathrm{~m}$ & $31.78 \mathrm{~m}$ & $0.23 \mathrm{~m}$ & $7.12^{\circ}$ \\
& FAST & $17.37 \mathrm{~m} / \mathrm{s}$ & $4.73 \mathrm{~m}$ & $31.13 \mathrm{~m}$ & $0.11 \mathrm{~m}$ & $6.26^{\circ}$ \\
Standard & FOWAT & $1.46 \mathrm{~m} / \mathrm{s}$ & $1.36 \mathrm{~m}$ & $3.84 \mathrm{~m}$ & $0.17 \mathrm{~m}$ & $1.16^{\circ}$ \\
Deviation & FAST & $1.96 \mathrm{~m} / \mathrm{s}$ & $1.49 \mathrm{~m}$ & $4.09 \mathrm{~m}$ & $0.22 \mathrm{~m}$ & $0.84^{\circ}$ \\
\hline
\end{tabular}

For this LC the range of motions show a good agreement with the mean values calculated by FAST. A slight over- or underestimation is observable for some of the minimum and maximum values, which could be due to the statistical estimation of the loads.

\subsection{Power generation performance}

The power of the FOWT has been calculated for a range of wind velocities and wave heights to simulate its specific power curve. The environmental conditions considered are regular waves and a steady wind velocity. A power curve has been computed for each of the wave heights as illustrated in Fig. 2. 


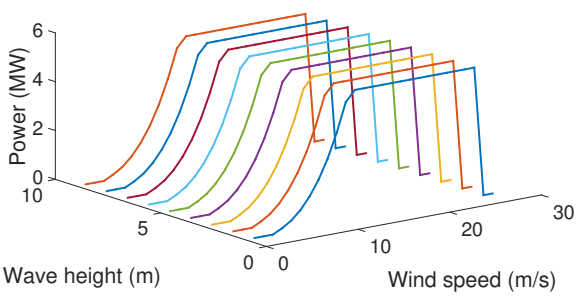

Fig. 2. Power curves for different waves

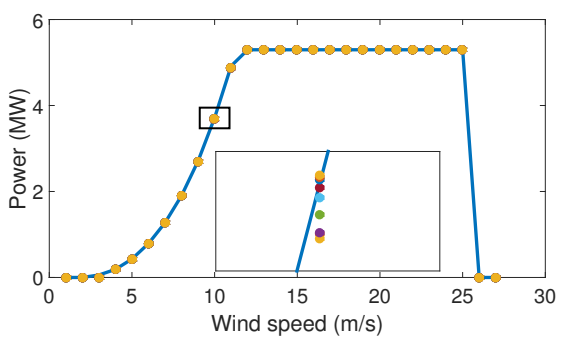

Fig. 3. Power curve comparison for LC 1

The power curves include the specific consideration for a FOWT as explained in Section 2.4 and the cut-in and cut-out wind speed limits of the wind turbine. It is observable that the FOWT behaves very stable to different wave heights, since the power curves are very similar. This behavior is very characteristic for a Spar-type floating substructure, because the deep draft and large inertia result in low heave and pitch motions in operating conditions [17]. Fig. 3 shows the comparison between the original power curve of the NREL BOWT and the ones obtained by the FOWT. The blue line represents the power curve of the BOWT and the one of the FOWT is marked by the dots. The subplot indicates the difference according to the wave heights. The power curve of the FOWT is nearly identical to the one obtained by the BOWT. Even the largest difference between the power curve of the BOWT and the most extreme wave is only smaller than $1 \%$. The power curve is computed next considering an environment with irregular waves and a turbulent wind velocity (Fig. 4), which represents a more realistic offshore scenario.

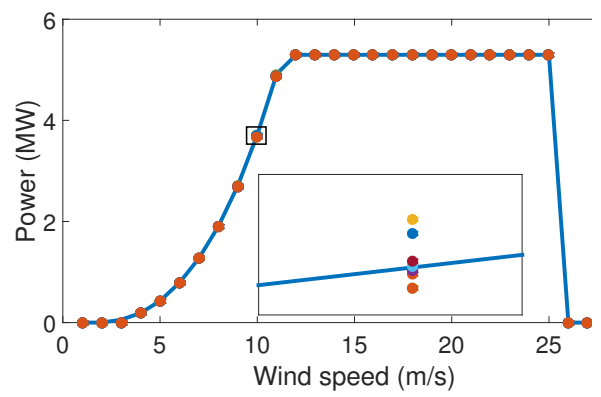

Fig. 4. Power curve comparison for LC 2

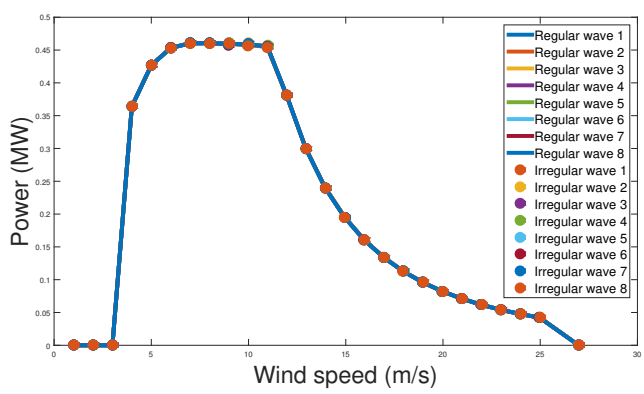

Fig. 5. Power coefficient comparison

It is observable that the power curves for the FOWT follow the power curve obtained by the BOWT. The largest difference between the power curve of the BOWT and the most extreme wave is about $1.1 \%$ and is, therefore, only slightly higher than compared to the regular wave and steady wind LC. Finally, Fig. 5 shows the power coefficient obtained for the FOWT and confirms that there is a non-significant difference between the LC and the waves. It can be concluded that the wind and wave loads have a non-significant effect on the power production performance of the OC3 Spar buoy FOWT and that the power generation is comparable with a BOWT. This performance has also been demonstrated in experimental tests of the Hywind and WindFloat prototypes in real offshore conditions [3].

\section{Conclusions}

In this paper, a simplified model has been presented for the static and dynamic analysis of a Spar buoy FOWT. It was investigated the effect of different LC on the platform motions and it was studied the potential difference in the power generation of a FOWT and a BOWT. The model was built by using MATLAB and the system response was evaluated for the surge, 
heave and pitch motions. The results have been compared with FAST, which is a well-known complex tool to model and simulate wind turbines. An overall good agreement has been found in the comparison of the structural properties computed by both models. Furthermore, the main motions and system's dynamics could be captured by the simpler model with an acceptable accuracy. In addition, the power generated by the FOWT has been computed for an environment with regular waves and steady waves as well as a LC consisting of turbulent wind and irregular waves. It was found that even for the most extreme conditions the power loss is less than $1 \%$ or $1.1 \%$, respectively the load case studied. This demonstrates the high power performance of the OC3-Hywind Spar buoy under different met-ocean conditions and also coincides with the experiences of prototype tests of FOWT demonstration projects. Further research is suggested to include the energy generation in the model, which can be used for a LCOE estimation. Besides that, the model could be applied to different offshore sites in order to investigate the performance of the FOWT in realistic met-ocean conditions.

\section{Acknowledgements}

This work was supported in part by the European Union Horizon 2020 programme under the grant agreement H2020-LCE-2014-1-640741.

\section{References}

[1] R. James, M.C. Ros, The Carbon Trust (2015)

[2] WindEurope, Floating Offshore Wind Vision Statement (WindEurope, 2017)

[3] J. Cruz, M. Atcheson, Floating Offshore Wind Energy: The Next Generation of Wind Energy (Springer, 2016)

[4] J. Jonkman, Tech. rep., National Renewable Energy Laboratory (NREL), Golden, CO. (2010)

[5] J. Jonkman, T. Larsen, A. Hansen, T. Nygaard, K. Maus, M. Karimirad, Z. Gao, T. Moan, I. Fylling, Tech. rep., National Renewable Energy Laboratory (NREL), Golden, CO. (2010)

[6] C. Curfs, Master's thesis, Delft University of Technology (2015)

[7] D.B. Fernando, d.B. Hernán, J.M. Ricardo, Wind Turbine Control Systems: Principles, Modelling and Gain Scheduling Design (Springer, 2006)

[8] J.M. Jonkman, Dynamics modeling and loads analysis of an offshore floating wind turbine (National Renewable Energy Laboratory (NREL), Golden, CO (United States), 2007)

[9] M. Karimirad, Offshore energy structures: for wind power, wave energy and hybrid marine platforms (Springer, 2014)

[10] S. Chakrabarti, Handbook of Offshore Engineering (2-volume set) (Elsevier, 2005)

[11] M. Masciola, J. Jonkman, A. Robertson et al., Implementation of a multisegmented, quasi-static cable model, in The Twenty-third International Offshore and Polar Engineering Conference (International Society of Offshore and Polar Engineers, 2013)

[12] M. Masciola, NREL. Available online: https://nwtc. nrel. gov/system/files/MAP_v0 (2013)

[13] M. Karimirad, T. Moan, Marine Structures 27, 45 (2012)

[14] E.E. Bachynski, T. Moan, Marine Structures 29, 89 (2012)

[15] J. Jonkman, W. Musial, Tech. rep., National Renewable Energy Laboratory (NREL), Golden, CO (United States) (2010)

[16] J. Jonkman, Inertial moments of oc3-hywind components, https://wind.nrel.gov/forum/ wind/viewtopic.php?t=748 (2016), accessed: 2018-03-07

[17] S. Nallayarasu, N.S. Kumar, Ships and Offshore Structures 12, 19 (2017) 